\title{
Posterior arterial circle of Willis anatomic variations and coronary artery dominance: is there a correlation?
}

\author{
David Gonçalves Nordon ${ }^{a}$, Aristeu de Almeida Camargo Neto \\ Rodrigo Rejtman Guimarães ${ }^{a}$, Orlando Fermozelli Rodrigues Júnior ${ }^{b}$
}

Nordon DG, Camargo Neto AA, Guimarães RR, Rodrigues Júnior OF. Posterior arterial circle of Willis anatomic variations and coronary artery dominance: is there a correlations? Autopsy Case Rep [Internet]. 2011;1(3):3-8. http://dx.doi.org/10.4322/acr.2011.002

\section{ABSTRACT}

Anatomic variations and anomalies in the arteries from the circle of Willis or the heart are common, sometimes even more common than the classic morphology. There is no reference in the literature to a correlation between variations and anomalies in these two organs. Coronaries and circle of Willis from 50 cadavers were dissected and analyzed. Eight percent presented a left dominant pattern of heart circulation, $4 \%$ were undetermined, and $88 \%$ were right dominant. Eighteen percent presented significant anomalies in the posterior circulation of the circle of Willis. The posterior cerebral artery originated from the internal carotid artery on the left in $2 \%$, on the right in $12 \%$, and on both sides in $4 \%$ of the cases. For every case that presented a left coronary dominant pattern, there was a concomitant anomaly in the posterior cerebral circulation $(p=0.0006)$. However, there is still no explanation for this finding.

Keywords: Coronary arteries; Cerebral arteries.

\section{INTRODUCTION}

The same arteries in different people are not necessarily equal; several differences in the anatomy of arteries may occur during the natural development of an individual, what is known as an anatomic variation. ${ }^{1}$ Trivellato et al. ${ }^{2}$ have outlined the requirements for a cardiac artery to be "normal" and "abnormal", differentiating anatomic variations from anomalies. Thus, the posterior interventricular artery (PIA) being originated either from the right or the left coronary is considered an anatomic variation of the cardiac arteries, as it does not compromise heart functioning.
Anatomic variations and anomalies in the arteries composing the circle of Willis are also quite common, as it is considered that only about one third have the classic morphology. ${ }^{3-5}$ Merkolla ${ }^{6}$ found that $46 \%$ of the posterior communicating arteries ( $\mathrm{PCoA}$ ) are missing in the general population; posterior cerebral arteries (PCA) originated from the internal carotid artery (ICA), known as fetal type PCA, are also relatively common. ${ }^{7}$ There is, however, to best of our knowledge, no data on the correlation of brain and heart vascular anatomic variations.

\footnotetext{
${ }^{a}$ Faculdade de Ciências Médicas e da Saúde de Sorocaba - Pontifícia Universidade Católica de São Paulo - Sorocaba/SP - Brazil. ${ }^{\text {b }}$ Departament of Pathology - Faculdade de Ciências Médicas e da Saúde de Sorocaba - PUC-SP, Sorocaba/ SP - Brazil.
} 
We are performing a study on the distribution of atherosclerosis in the arteries and during the dissections both anatomic variations and anomalies in circle of Willis and coronaries were registered. The objective of this study is to present cases of concomitant anatomic variations in the brain and heart arterial circulation and speculate about an association between them.

\section{Methods and Casuistic}

This study was approved by the Ethics in Research Committee from Centro de Ciências Médicas de Sorocaba, in June, 2010. Written informed consent was signed by the next of kin or legal guardian. Cadavers from patients aged 40 years old or more were included when all three organs (brain, heart and kidneys) were available for dissection.

The organs were extracted and fixed in 10\% formaldehyde for no longer than a week, before being dissected.

\section{Cardiac Arteries}

The cardiac arteries were dissected by using a small Spencer scissor and a small rattooth forceps; the arteries were dissected from their end to their origin, avoiding damaging both the heart and the vessel itself; initially the posterior wall, then the anterior wall, finally the aorta for the left coronary, then the marginal artery and the aorta for the right coronary. Once dissected, the whole arterial bed comes out as a single piece, what allows the evaluation of every macroscopic superficial arterial anastomosis and variations. Arterial branches that perforated the cardiac muscle were not evaluated.

The cardiac pattern of dominance was defined as the artery that supplied the posterior interventricular groove on macroscopic analysis, and could be either right, if it were the PIA or the right marginal artery, or left, if it were the anterior interventricular artery (AIA) or the circumflex. Myocardial bridging was recorded when a main coronary artery penetrated the myocardium during its track. It was not evaluated for other branches.

\section{Cerebral Arteries}

The anterior cerebral arteries (ACA) were extracted from their origin in the ICA until the division at the frontopolar artery; the middle cerebral arteries (MCA) were dissected from their origin until their first ramification after the generation of lenticular-striate arteries; the PCA were dissected from their origin, either the basilar artery (BA) or the ICA, until the ramification in two branches: the parieto-occipital and calcarine arteries. The PCOA and anterior communicating artery ( $\mathrm{ACo} A)$ were also obtained for each specimen.

The most important anatomic variations and anomalies were enumerated, before the arteries were divided and sent for microscopic analysis. Preventing the circle of Willis from maintaining an adequate flow (that is, as defined by Alpers, ${ }^{8}$ one in which blood can circulate from any entrance point and return to that same point) was considered as the basic criterion for being regarded as an anomaly, whereas other morphological differences were regarded as anatomic variations.

Therefore, extra arteries or uncommon anastomosis were considered as anatomic variations, whereas the absence of arteries, no communication between them, and abnormal origin were considered as anomalies. A small diameter was considered as an anatomic variation only if the artery was smaller when compared to the contralateral artery.

\section{Statistical Analysis}

The Fisher's exact test was performed to compare the pattern of dominance and the anatomic variations; statistical significance was considered when $p<0.05$.

\section{RESULTS}

Fifty cadavers were obtained for this analysis. Thirty two (64\%) were male; mean age was 60.4 years.

The most common cause of death was respiratory failure $(36 \%)$, followed by heart failure $(22 \%)$, shock $(14 \%)$ and others $(8 \%)$. The cause of death could not be determined in 10 cases $(20 \%)$. 
Table 1 - Patterns of coronary circulation in cases with posterior circle of Willis anomalies

\begin{tabular}{|c|c|c|c|c|}
\hline \multicolumn{3}{|c|}{ Brain arteries } & \multicolumn{2}{|c|}{ Heart arteries } \\
\hline & & $\mathbf{n}$ & Dominance & Other alterations \\
\hline \multirow{4}{*}{$\begin{array}{l}\text { Right PCA originated from } \\
\text { right ICA. }\end{array}$} & & 6 & & Short Cx \\
\hline & No other alteration. & 3 & $\begin{array}{l}R \\
R \\
L\end{array}$ & $\begin{array}{c}\text { Short Cx } \\
\text { Cx from RCA } \\
\text { Short Cx, RCA and PIA }\end{array}$ \\
\hline & No right $\mathrm{PCoA}$. & 2 & $R, L$ & - \\
\hline & No PCoA. & 1 & $\mathrm{R}$ & Short Cx \\
\hline $\begin{array}{l}\text { Both PCA originated from ICA. } \\
\text { No connection to the BA. }\end{array}$ & & 2 & $\begin{array}{l}\mathrm{L} \\
\mathrm{L}\end{array}$ & $\begin{array}{c}\text { Hipoplastic right circulation } \\
-\end{array}$ \\
\hline $\begin{array}{l}\text { PCA originated from the left ICA. } \\
\text { No left PCoA. }\end{array}$ & & 1 & $\mathrm{R}$ & Short Cx \\
\hline
\end{tabular}

Subtilte: PCA: Posterior cerebral artery. ICA: Internal carotid artery. Cx: Circumflex artery. RCA: Right coronary artery. PCoA: Posterior communicating artery. BA: Basilar artery.

Fifty dissections were performed from August, 2010, to July, 2011; of these, nine brains $(18 \%)$ showed anomalies affecting the PCA (Table 1). Six (12\%) right PCA originated from the right ICA; one (2\%) left PCA originated from the left ICA; and in two brains (4\%), both PCAs originated from both ICAs; in both these cases there was no connection between the basilar artery and the PCA. In sixteen brains (32\%) PCoA were missing: right in $6(12 \%)$; left in $3(6 \%)$ and both in $7(14 \%)$.

Variations or anomalies in the circle of Willis were detected in 25 cases (50\%). There was predominance in the right posterior circulation of the circle of Willis: 12 cases (48\%). Alterations in the left circulation and in both sides were respectively detected in $4(16 \%)$ and in $9(36 \%)$ cases.

Anatomic variations in the cardiac arteries were also found. The PIA originated from the left coronary in 3 cases $(6 \%)$. In one case $(2 \%)$, the origin of the PIA could not be defined since the patient had Chagas' disease, and not only the vessels' anatomy was hard to be evaluated, but also their histology was very similar to veins, rather than arteries. In one case $(2 \%)$, PIA was duplicated and originated from both the left (LCA) and the right coronary artery (RCA), and both supplied the interventricular groove. These two cases were excluded from further statistical analysis. Two cases (4\%) presented myocardial bridging; however, they did not have any other coronary anatomical alteration. In one case $(2 \%)$, right circulation was hypoplastic and most of the posterior wall depended on diagonal branches
Table 2 - Comparison between coronary dominant pattern and significant anomalies in the posterior segment of Circle of Willis. ( $p$ according to Fisher's exact test)

\begin{tabular}{cccc}
\hline \multicolumn{4}{c}{ Significant anomaly of the circle of Willis } \\
\hline $\begin{array}{c}\text { Heart } \\
\text { dominance } \\
\text { pattern }\end{array}$ & $\begin{array}{c}\text { Present } \\
\mathbf{n}(\%)\end{array}$ & $\begin{array}{c}\text { Absent } \\
\mathbf{n}(\%)\end{array}$ & $p$ \\
\hline Right & $5(10.4)$ & $39(81.3)$ & 0.0006 \\
Left & $4(8.3)$ & $0(0)$ & \\
\hline
\end{tabular}

from the LCA. Therefore, this case was considered as left-dominant.

In total, the heart presented a right dominant pattern in $88 \%$ of cases, left in $8 \%$, and undetermined in $4 \%$ of all cases.

Anomalies in the posterior segment of the circle of Willis were detected in the 4 cases of left coronary dominant pattern. In 2 cases both PCA originated from ICA, with no connection to the BA. In other two cases right PCA originated from right ICA. In one of these the right PCoA was absent. The association between left coronary dominance and anomalies in the posterior segment of the circle of Willis was statistically significant $(p=0.0006)$ (Table 2).

Pictures of a left-dominant heart (Figure 1) and its respective circle of Willis (Figure 2) are shown below. 


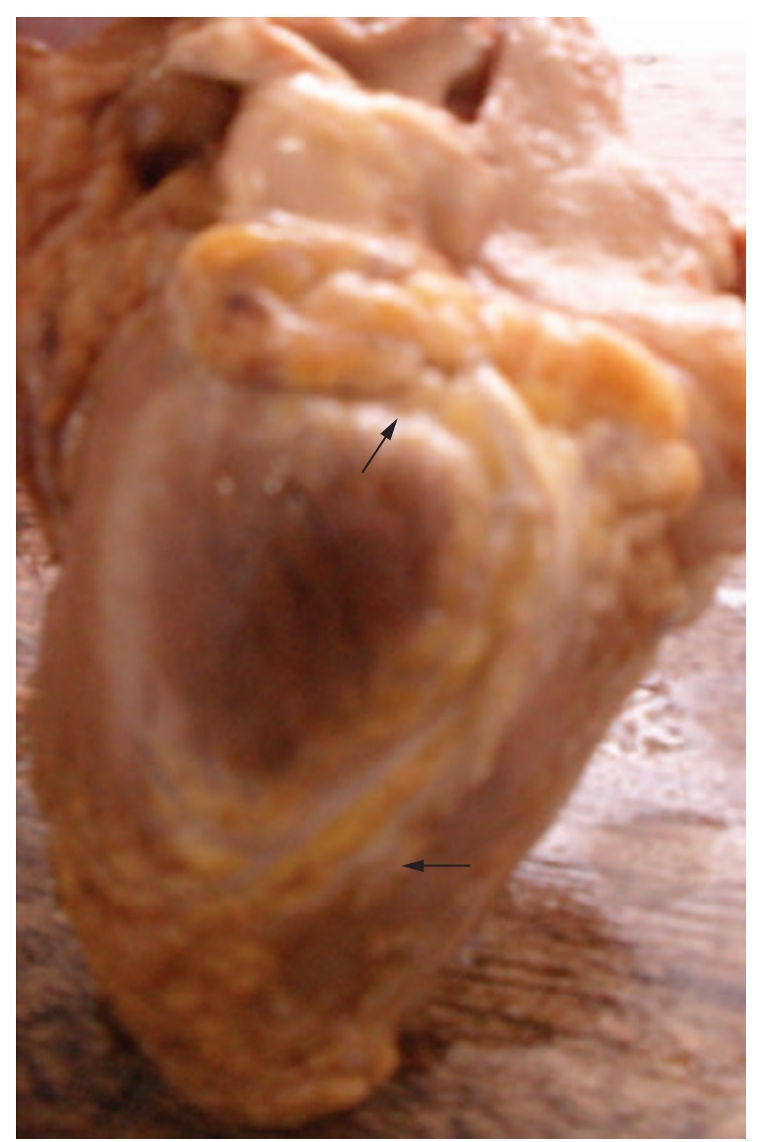

Figure 1 - Heart with PIA originated from the LCA (arrows).

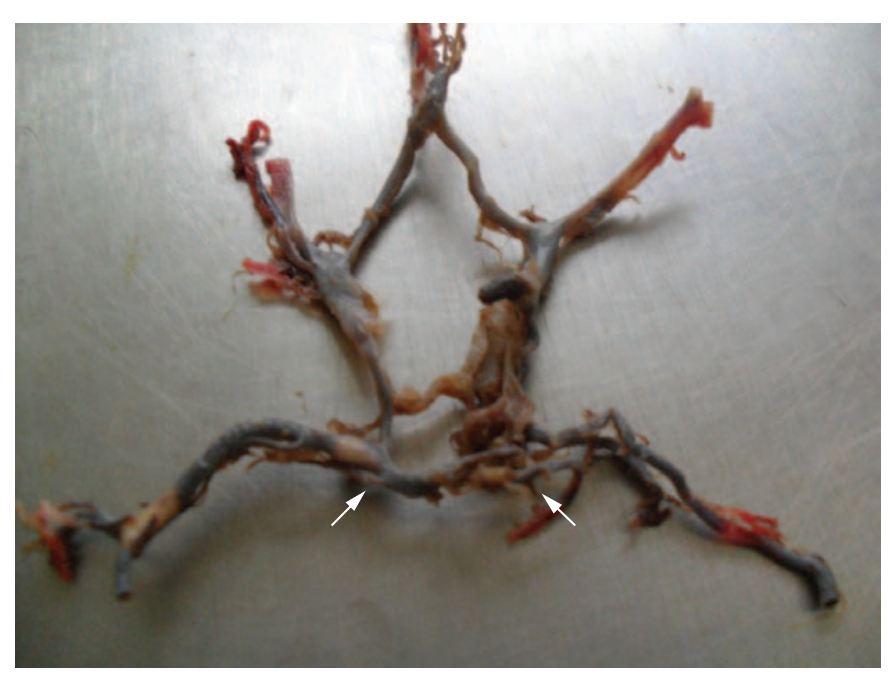

Figure 2 - Dissected circle of Willis showing a variant connection between both posterior cerebral arteries and no connection to the basilar artery (arrows).

\section{DISCUSSION}

Six $(66.7 \%)$ of the 9 cases of significant anomalies in posterior circulation in the circle of Willis presented here were men, mean age of
63.7 years. The most common cause of death was respiratory failure due to pneumonia (44.4\%). Gender, age and cause of death were similar to the rest of our sample. None of the stated causes of death or commorbidities could explain the anatomic anomalies observed in these cases.

Eight percent of the cases had a left coronary dominant pattern, and $4 \%$ had an undetermined pattern, adding up to $12 \%$, which is in accordance with the literature..$^{1,9-11}$ Such macroscopic analysis is, however, not thoroughly adequate since coronary dominance is currently defined by angiography. This method generates a better analysis of the apex's blood supply and is less prone to mistake. Even the vessels that penetrate the cardiac muscle can be evaluated, as opposed to the macroscopic dissection, which may neglect microscopic anastomosis between the left and right circulation.

Other studies analyzed the cardiac arteries through dissection ${ }^{12,13 .}$. Fazliogullari et al. ${ }^{12}$ identified a right dominance in $42 \%$, co-dominance in $44 \%$, and left dominance in $14 \%$, what is rather different from the literature and from our findings. This may be due to their technique, as dissection was performed in layers, as opposed to ours, that focused on obtaining the arteries as well as not damaging the heart.

Diminished diameter of the arteries in the circle of Willis was not considered an anomaly. Only the cases in which the PCoA was definitely missing were recorded. If diminished diameter of the PCoA had been considered an anomaly, the number of anomalies in the circle of Willis would be certainly larger, as commented by Routsonis. ${ }^{5}$

One case report describes an incidental finding of bilateral internal carotid congenital agenesis in an 11-year-old child. ${ }^{14}$ Another report presents a woman whose right PCA was the only branch of the right ICA. ${ }^{15}$ In both cases, brain perfusion depended solely on the vertebral arteries and on the integrity of the circle of Willis. Such anomalies are especially important when performing surgery on the thoracic aorta or the carotids, when brain perfusion must be maintained exclusively by one side of the circle of Willis.

Arteries from the circle of Willis are formed from a primitive network surrounding the neural tube in the embryo. First, both carotid arteries are formed; then, they divide into branches which will 
form the anterior cerebral artery, the PCoA and both segments P2 and P3 of the PCA. All the other arteries are additional branches to the primitive ring. As the fetus develops, the PCoA diminish, whereas the segment $\mathrm{P} 1$ develops and the PCA acquires the classic morphology, originated from the BA. ${ }^{16-19}$

Coronary arteries are formed rather differently; first, the septum transversum grows out to form a structure on the sinoatrial pole of the heart: ${ }^{20-22}$ the proepicardial organ. Such organ will generate the whole epicardium. The epithelial cells will then transform into mesenchymal cells (epithelial to mesenchymal transition) which will generate primitive vessels, dependent on FOG$2 .{ }^{23}$ The epicardium of the atrioventricular sulcus contains an abundance of mensenchymal cells and generates the first coronary vessels which are basically channels within the connective tissue..$^{20,24}$ Further on, other mesenchymal cells gather around and form the arterial smooth muscle. ${ }^{25}$ Despite not having any blood flow, these cells fuse in order to form vessels which will afterwards penetrate the aorta. ${ }^{26}$ It is known that coronary arteries are constantly remodeled during their development, however there is still little certainty on the remodeling process itself, and several gene products have been implicated. ${ }^{27-29}$

We found a significant correlation between the posterior cerebral circulation anomalies and the left dominant pattern of the heart circulation; however, to the best of our knowledge, there is no reference in the literature or possible explanation for that. As the arteries present different formation processes, one can speculate that such correlation depends on the apoptosis regulation process and possibly a gene that is common for both organs.

Despite presenting a significant correlation, this sample is still small and cannot be generalized. Further studies need to be developed by using imaging techniques such as magnetic resonance and angiography. There were limitations in the definition of coronary dominance pattern used in this study as already mentioned. However, the frequency of coronary dominance patterns in this study was much more similar to what is found in the literature than other autopsy studies.

The most widely used technique for the anatomical study of an organ's arteries is the injection of resins into the vessels and further corrosion of the organ, as described by Tompsett. ${ }^{30}$ As the original aim of this study was to evaluate atherosclerotic plaques within the arteries, the authors chose not to use such technique, thus possibly compromising thorough evaluation of all anastomosis within the cardiac muscle, as commented above. Further anatomical studies may, however, prefer such technique.

Twenty percent of cases had no explained cause of death. Despite the cadavers being analyzed for focal ischemia and hemorrhages both in the heart and brain, it is possible that vascular anomalies were the main cause of death, as well as non-investigated metabolic causes.

\section{ACKNOWLEDGEMENTS}

We are grateful for Mr. Claudio Theodoro and Mr. Marcos Antonio Bego, autopsy technicians who have been helping us throughout our work.

\section{REFERENCES}

1. Di Guglielmo L, Montemartini C. Variations anatomiques et anomalies congenitales des arteres coronaires. Experience personelle. Ann Radiol. 1975;18:255-7.

2. Trivellato M,Angelini PP, Leachman RD. Variations in coronary artery anatomy: Normal versus abnormal. Cardiovasc. Dis. 1980;7:357-70. PMid:15216239. PMCid:287879.

3. Kleiss E. Die verschiedenen Formen des circulus arteriosus Willisii. Anat Anz. 1941;92:216-30. German.

4. Mittlewallner F. Variationsstatistische Untersuchungen an den basalen Hirngefässen. Acta Anat. 1955;24:51-87. German. http://dx.doi.org/10.1159/000141019

5. Routsonis KG, Stamboulis E, Cristodoulaki M. Anomalies of the circle of Willis and atherosclerosis. Vasc Surg. 1973;7:141-5. PMid:4716630.

6. Merkkola P, Tulla H, Ronkainen A, et al. Incomplete circle of Willis and right axillary artery perfusion. Ann Thorac Surg. 2006;82:74-80.

7. Morris, PP. Cerebral vascular anatomy. Neuroimaging Clin N Am. 1996;6:541-60. PMid:8873092.

8. Alpers BJ, Berry RG, Paddison RM. Anatomical studies of the circle of Willis in the normal brain. Arch Neurol Psychiat. 1959;81:409-18.

9. Cademartiri F, La Grutta L, Malagò R, et al. Prevalence of anatomical variantand coronary anomalies in 543 consecutive patients studied with 64-slice CT coronary angiography. Eur 
Radiol. 2008;18:781-91. PMid:18246357. PMCid:2270369. http://dx.doi.org/10.1007/s00330-007-0821-9

10. Abdellah AAA, Elsayed ASA, Hassan MA. Angiographic coronary artery anatomy in the Sudan Heart Centre. Khartoum Med J. 2009;2:162-4.

11. Kosar P, Ergun E, Öztürk C, Kosar U. Anatomic variations and anomalies of the coronary arteries: 64-slice CT angiographic appearance. Diagn Interv Radiol. 2009;15:275-83. PMid:19957241.

12. Fazliogullari Z, Karabulut AK, Unver Dogan N, Uysal II. Coronary artery variations and median artery in Turkish cadaver hearts. Singapore Med J. 2010;51:775-80.

13. Bhimalli S, Dixit D, Siddibhavi M, Shirol VS. A study of variations in coronary arterial system in cadaveric human heart. World J Sci Technol. 2011;1:30-5.

14. Rumboldt Z, Catillo M, Solander S. Bilateral congenital absence of the internal carotid artery. Eur Radiol. 2003;13:130-2. PMid:16440235. http://dx.doi.org/10.1007/ s00330-002-1742-2

15. Rothberg M, Mattey WE, Bastidas J. Anomalous internal carotid-posterior cerebral artery circulation: one form of congenital incomplete circle of Willis. Am J Roentgenol. 1977;128:153-5. PMid:401577.

16. De Vriese B. Sur la signification morphologique des arteries cerebrales. Arch Biol. 1905;21:357-457.

17. Vander Eckken H. Discussion of "collateral circulation" of the brain. Neurology. 1961;11:16-9. PMid:13780135.

18. Riggs HE, Griffith J. Anomalies of the circle of Willis in persons with nervous and mental disorders. Arch Neurol Psychiatr. 1938;39:1353-6.

19. Saeki N, Rhoton ALJ. Microsurgical anatomy of the upper basilar artery and the posterior circle of Willis. J Neurosurg. 1977;46:563-78. PMid:845644. http://dx.doi.org/10.3171/ jns.1977.46.5.0563

20. Viragh S, Challice CE. The origin of the epicardium and the embryonic myocardial circulation in the mouse. Anat
Rec. 1981;201:157-68. PMid:7305017. http://dx.doi. org/10.1002/ar.1092010117

21. Manner J. Experimental study on the formation of the epicardium in chick embryos. Anat Embryol. 1993;187:281-9. http://dx.doi.org/10.1007/BF00195766

22. Gittenberger-de Groot AC, Peeters MPV, Mentink MM, Gourdie RG, Poelmann RE. Epicardium-derived cells contribute a novel population to the myocardial wall and the atrioventricular cusions. Cir Res. 1998;82:1043-52. PMid:9622157.

23. Tevosian SG, Deconinck AE, Tanaka M et al. FOG-2, a cofactor for GATA transcription factors, is essential for heart morphogenesis and development of coronary vessels from epicardium. Cell. 2000;101:729-39.

24. Wada AM, Reese DE, Bader DM. Bves: prototype of a new class of cell adhesion molecules expressed during coronary artery development. Development. 2001;128:2085-93.

25. Poelmann RE, Gittenberger-de Groot AC, Mentick MMT, Bokenkamp R, Hogers B. Development of the cardiac coronary vascular endothelium, studied with antiendothelial antibodies, in chicken-quail chimeras. Circ Res.1993;73:559-68.

26. Manner J. Does the subepicardial mesenchyme contribute myocardioblasts to the myocardium of the chick embryo heart? A quail-chick chimera study tracing the fate of the epicardial primordium. Anat Rec.1999;255:212-26.

27. Gale NW, Yancopoulos GD. Growth factors acting via endothelial cell-specific receptor tyrosine kinases: VEGFs, angiopoietins, and ephrins in vascular development. Genes Dev.1999;13:1055-66.

28. Carmeliet P. Mechanisms of angiogenesis and arteriogenesis. Nat Med. 2000;6:389-95.

29. Oettgen P. Transcriptional regulation of vascular development. Circ Res. 2001;89:380-8.

30. Tompsett $\mathrm{DH}$. Improvements in corrosion casting techniques. Ann Roy Coll Surg Engl. 1959;24:110-23. PMid:13627967. PMCid:2413772.

Conflict of interest: None.

Submitted on: $30^{\text {th }}$ May 2011

Accept on: $1^{\text {st }}$ August 2011

Correspondence: David Gonçalves Nordon

E-mail:d-nordon@uol.com.br 